\title{
Multisource Disaster Chain and Control in Regional Water Environment of the Dongjiang Lake in China
}

\author{
Feng Gao*, Ronglan Xiao \\ School of Resources and Safety Engineering, Central South University, Changsha, China \\ Email: csugaofeng@126.com
}

Received 25 August 2015; accepted 27 September 2015; published 30 September 2015

Copyright (C) 2015 by authors and Scientific Research Publishing Inc.

This work is licensed under the Creative Commons Attribution International License (CC BY). http://creativecommons.org/licenses/by/4.0/

\section{(c) (i) Open Access}

\section{Abstract}

On the background of analysis on region water environment safety in the Dongjiang Lake of southcentral China, the source of pollution of water environment and its control are studied. The concept of region environment disaster chain is put forward on the basis of combination study on the disaster chain theory and pollution problem in regional water environment. Through identification and analysis of pollution disaster resources in regional water environment of the Dongjiang Lake, the annual emission of the chemical oxygen demand (COD), ammonia nitrogen, total phosphorus (TP) and heavy metal (Cd, As, Pb) are counted. According to evaluation on structure proportion of contaminants in the Dongjiang Lake, agricultural non-point source is the uppermost pollution source, which accounted for $\mathbf{8 7 . 7 4 \%}$ in total pollution load. Ammonia nitrogen, TP and COD are mainly contaminants accounted for $94.27 \%$ in total pollution load. By analyzing danger of contaminants in the lake, basic form of disaster chain of water environment pollution is built elementarily. It shows characteristics of branches and trunk basin disaster chain and embodies multisource disaster implication chain caused by human activities. Then, disaster resources chaincutting methods for pollution prevention and control of regional water environment of the Dongjiang Lake are analyzed.

\section{Keywords}

Regional Water Environment, Disaster Chain, Chain-Cutting Disaster Mitigation from Gestation Source, Water Pollution, Control, The Dongjiang Lake

\footnotetext{
${ }^{*}$ Corresponding author.
}

How to cite this paper: Gao, F. and Xiao, R.L. (2015) Multisource Disaster Chain and Control in Regional Water Environment of the Dongjiang Lake in China. Journal of Water Resource and Protection, 7, 1174-1182. 


\section{Introduction}

The Dongjiang Lake is located in Hunan Province of China, and on the juncture of Guangdong and Jiangxi provinces (Figure 1). It is a large reservoir in upstream of the Leishui River, the primary tributary of the Xiangjiang River, with the water surface area of $160 \mathrm{~km}^{2}$ and a total capacity of 9.74 billion $\mathrm{m}^{3}$, which is known as the "Dongting of Southern Hunan". The region affected by its water reaches to more than $4700 \mathrm{~km}^{2}$, and about 13 million urban population are affected within the scope of Changsha, Zhuzhou, Xiangtan, Hengyang and Chenzhou-five urban agglomerations and its surrounding area, accounting for 55\% of the Hunan provincial urban population. Therefore, the Dongjiang Lake water resources protection has important meaning to guarantee water security on the influenced region, and it is also a major demand of national sustainable development of advanced demonstration area construction for Zixing, which is one of county-level cities of Chenzhou by the lake. However, with the sustained social and economic development, the Dongjiang Lake is threatened by a variety of sources from agriculture, industry, fisheries, tourism, and so on. Especially since the 1960s, the stripping from the long-term exploration of mineral resource, the tailings and the waste left after harvest have caused severe negative environmental effects.

Since the 1990s, water security has become the focus of academic and social sectors; the theory of water environment safety has been conducted at home and abroad, but has not yet formed a systematic and scientific theoretical system [1]. It is generally believed that water shortages and water pollution are two major factors that affect water security. In fact, water pollution is a form of environment disasters. Due to environment disasters related to natural, human, social and other aspects, its research is extremely broad, including systematic, comprehensive, applications and diverse research methods.

Disaster chain is a kind of disaster research methods founded by Chinese scholars. Based on the relationship of earthquake and its secondary disasters, in 1987, seismologists Guo Zengjian first proposed the concept of disaster chain theory and its classification [2], and pioneered a new method in disaster science. Subsequently, many scholars have made related researches and definitions [3]-[5].

Focused on the environment security issues of the Dongjiang Lake, this paper analyzed the pollution situation and prevention issues of regional water environment in the Dongjiang Lake at first, and then discussed the manifestation and treatment measures of multi-source regional environment disaster chain in ore district of the lake from the perspective of disaster chain, providing technical supports to protect the water resources of the lake and its ecosystem.

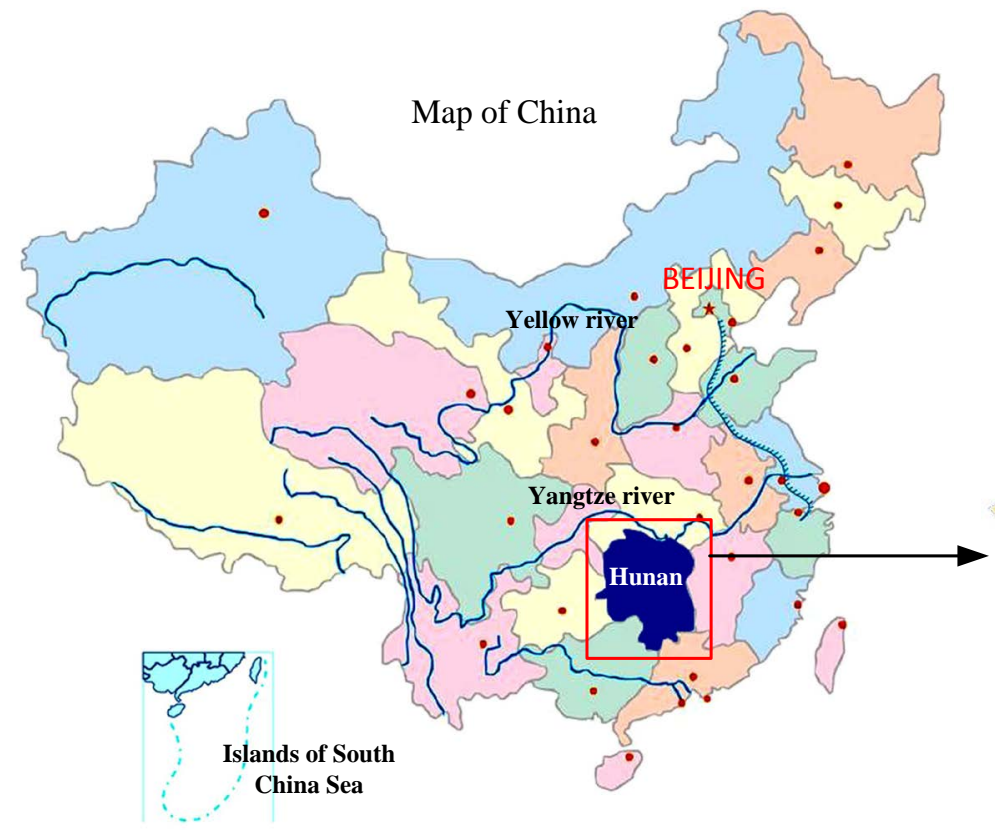

Map of Hunan Province

Figure 1. Dongjiang Lake basin location. 


\section{Regional Environment Disaster Chain}

\subsection{The Meanings of Disaster Chain}

Because of the universality of the disaster's concept, there is no strict unified definition to disaster chain. Paper [6] put forward that disaster chain is the general appellation of the chaining relations which abstracts each kinds of natural or man-made disasters to have vector common reactive features, to depict the related material information process of single or several disasters, including formation, penetration, interference, transformation, decomposition, synthesis, coupling and so on, until disasters cause losses and destruction to human society.

From various definitions of disaster chain concept we can found the essence that they both abstract the common of disasters as the starting point, emphatically reflecting the features of connection, restriction, non-independence and interaction between disasters. Namely the need for understanding the disaster should from the view of entire disaster process and macro disaster system, then cooperate with the disaster causes, the process, and the outcome research of the various subsystems (small disaster events) in disaster system.

\subsection{The Development of Disaster Chain}

As the disaster chain theory only formed from twenty years ago, there are several problems need to be improved in the future, on the one hand, the recognize of concept is still inconsistent, most studies limited to gestation and induced processes of natural disasters, on the other hand, the relative study to disasters from micro-bred to macro performance of vectors is deficit.

In 2007, the Second Disaster Chain Symposium on the theme of urban disaster chain and its countermeasures developed the research and concept of disaster chain. In 2008, China Association held the 16th New Ideas New Doctrine Academic Salon, with the theme of the evolution, forecasting methods and countermeasures of the major disaster chain [7], which played a tremendous role on the knowledge and research of disaster chain. In recent years, the application of disaster chain is further extended, besides the classic disaster chain in which the main constituents are the early four types of natural disasters (earthquakes, typhoons, cold wave and drought), many corresponding theoretical discussions and applications are also carried out in the agricultural system, mining area water disaster, geologic environment hazard, urban disaster, etc.

\subsection{Regional Environment Disaster Chain}

According to the definition of disaster: disaster $(D)$ is the product of hazard inducing environment $(E)$, hazard inducing factors $(H)$ and hazard bearing body $(S)$ combined, namely:

$$
D=E \cap H \cap S
$$

where $H$ is the sufficient condition of disasters, $S$ the necessary condition of amplification or reduction, $E$ the background conditions to influent $H$ and $S$.

According to the existing results, research of disaster chain can be generally divided into two types, one is from the disaster category ( $D$, mainly from the natural disasters), to study the relationship of chain effect between various disasters, such as earthquake disaster chain, typhoon-rainstorm disaster chain, drought disaster chain and so on, which are tend to focus on theory and reflecting similarities; the other is from the hazard inducing environment $(E)$, to study chain effect of disaster $(D)$ within a specific region, for example, environment disaster chain in specific area, which in favor of combining theory with practice and reflecting the personality. The later has being investigated extensively, such as floods disaster chain in Minjiang River, typhoon disaster chain in Guangdong Province. In fact, any disaster in a particular area is the result from the joint effects of $H, E$ and $S$, while the hazard inducing environment $(E)$ is the determinant of disaster researching content and extent.

In addition, the chain effect reflects a dynamic process, the disaster evolution is a continuous state, and disaster chain contains the objective law of changes from quantitative to qualitative.

\section{Regional Water Environment Disaster Sources and Evaluation}

\subsection{Water Environment Disaster Sources of the Dongjiang Lake}

Chenzhou city, where the Dongjiang Lake belongs, is known as the "land of nonferrous metals". The mineral resources play an important role in its regional industry. Therefore industrial pollution is the major disaster 
sources of environmental pollution in Dongjiang Lake. From the view of industry distribution of pollution sources, the majority of key industrial pollution sources in the region focused on mining and dressing (Figure 2), which accounted for $66 \%$, followed by smelting, chemical, building materials and medical care. According to statistics, the total polluted area of mines reached to $18.13 \mathrm{~km}^{2}$, the total existing waste rock, tailings and waste residue up to 2 million tons, the exceeding standard rate of heavy metals (Cd, As, $\mathrm{Pb}$, etc.) in the non-ferrous mining soil is 2 to 8.5 times.

Although the first industry in Dongjiang Lake felled by nearly $12 \%$ in the share of three industries structure for the past decade, the internal structure of the agricultural industry has been relatively stable [8]. While the complexity of the agricultural structure and the direct emissions are the main reasons to the increase of water TN (TN total nitrogen) and TP (TP total phosphorus). In addition, urban life, tourism, oil contamination from water transportation and fish farming are also the pollution sources of water environment in Dongjiang Lake. The statistics of annual pollutants emission [9] from pollution sources above are shown in Table 1.

\subsection{Evaluation on Structure Proportion of Contaminants}

In this paper, the equal standard pollution load method is applied to evaluate the structure proportion of pollutants. By taking the pollutant emission standards or corresponding environment quality standards as evaluation criteria, and comparing the total amount of one pollutant with the pollutant emission standards, we can obtain an amount comparable to each other on the same scale. Relative formulas are as follows.

$$
\begin{gathered}
P_{i}=\frac{Q_{i}}{C_{O i}} \times 10^{-6} \\
K_{i}=\frac{P_{i}}{\sum P_{i}} \times 100 \%
\end{gathered}
$$

where $P_{i}$ is the equal standard pollution load of pollutants $i\left(\mathrm{~m}^{3} \cdot \mathrm{a}^{-1}\right), Q_{i}$ the emissions of $i\left(\mathrm{t} \cdot \mathrm{a}^{-1}\right), C_{o i}$ the standard value of water quality control category based on water environment function zoning (according to surface water quality standards of China, GB3838-2002) of pollutant $i\left(\mathrm{mg} \cdot \mathrm{L}^{-1}\right), K_{i}$ the equal standard pollution load ratio of pollutant $i$.

According to Table 1, the total pollutants of 6 sources were in sequence of COD, ammonia nitrogen, TP, oil,
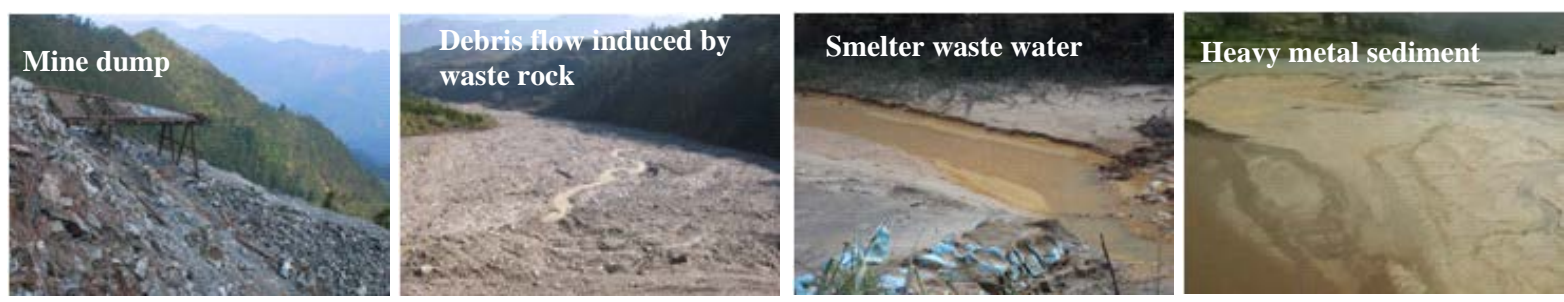

Figure 2. Environment pollution caused by extensive mining, processing and smelting.

Table 1. Data statistics of annual emission of pollutants.

\begin{tabular}{cccccccc}
\hline Pollution sources & COD/t & TP/t & $\begin{array}{l}\text { Ammonia } \\
\text { nitrogen/t }\end{array}$ & Oil/t & As/t & Cd/t & Pb/t \\
\hline Industry & 691.64 & & 4.60 & & 0.995 & 0.168 & 0.108 \\
Agriculture & 25578.91 & 586.03 & 4803.45 & & & \\
Urban living & 3585.25 & 26.87 & 268.74 & & & \\
Tourism & 249.6 & 1.56 & 15.6 & & & \\
Water transportation & & & & & & \\
Aquaculture & 112.45 & 0.62 & 4.94 & & & \\
Total & 30217.85 & 615.08 & 5079.33 & 26.67 & 0.995 & 0.168 & 0.108 \\
\hline
\end{tabular}


As, $\mathrm{Cd}$ and $\mathrm{Pb}$. According to surface water quality standards (GB3838-2002), the evaluation criterion in Table 2 was applied to calculate the equal standard pollution load of each pollution source and its ratio.

On the basis of formula (1), (2) and Table 2, the calculation results are given in Table 3, that the equal standard pollution load of each pollutant were in descending order of ammonia nitrogen (49.62\%), TP (29.94\%), COD (14.71\%), oil (5.19\%) and heavy metals (Cd, As, $\mathrm{Pb})(0.54 \%)$. This shows that the main pollution source in the Dongjiang Lake is agricultural non-point source, which account for $87.74 \%$, and the main pollutants were ammonia nitrogen, TP, COD, whose equivalent pollution load represent $94.27 \%$ of the total load. According to the perennial monitoring data, the water quality of Dongjiang Lake is generally good to reach even more than the national II class standard in China. However, some sectional monitoring data show an increase in nutrient quality of local waters, with water quality mainly controlled by heavy metals $\mathrm{Cd}$ and $\mathrm{TN}$, TP, and part of regions in middle nutrient levels [10].

\section{Multi-Sources Catastrophic Chain and Its Control in Regional Water Environment}

\subsection{Multi-Sources Catastrophic Chain Model of Regional Water Environment}

Water pollution of Dongjiang Lake is mainly due to human's manufacture and life. According to disaster chain theory, the regional water environment in Dongjiang Lake is hazard inducing environment, the various pollutants are the hazard factors, and the final output morphology of disaster is both at the expense of the physical health of people, animals and plants in the lake area. Therefore, from the perspective of disaster chain, water environment pollution in the Dongjiang Lake generally belongs to multisource disaster implication chain caused by human activities, with characteristics of branches and trunk basin disaster chain [11]. Then we can construct the schematic diagram (Figure 3) of disaster chain of water environment pollution in the Dongjiang Lake.

According to Figure 2, there are $i$ sub-chains of water pollution disaster induced by six kind of pollution sources. All these sub-chains can be divided into two types: direct and indirect disaster chain of water environment pollution. During the chain effect of disaster, assuming that there are $k$ disaster

Table 2. Evaluation criterion of pollutants.

\begin{tabular}{cccccccc}
\hline Pollutant name & $\begin{array}{c}\mathrm{COD} \\
(\mathrm{mg} / \mathrm{L})\end{array}$ & $\begin{array}{c}\mathrm{TP} \\
(\mathrm{mg} / \mathrm{L})\end{array}$ & $\begin{array}{c}\text { Ammonia nitrogen } \\
(\mathrm{mg} / \mathrm{L})\end{array}$ & $\begin{array}{c}\text { Oil } \\
(\mathrm{mg} / \mathrm{L})\end{array}$ & $\begin{array}{c}\mathrm{As} \\
(\mathrm{mg} / \mathrm{L})\end{array}$ & $\begin{array}{c}\mathrm{Cd} \\
(\mathrm{mg} / \mathrm{L})\end{array}$ & $\begin{array}{c}\mathrm{Pb} \\
(\mathrm{mg} / \mathrm{L})\end{array}$ \\
\hline Evaluation criteria & 20 & 0.2 & 1 & 0.05 & 0.05 & 0.005 & 0.05 \\
\hline
\end{tabular}

Table 3. The equivalent load of mainly pollutants in the Dongjiang Lake basin.

\begin{tabular}{|c|c|c|c|c|c|c|c|c|}
\hline \multirow[b]{2}{*}{$\begin{array}{l}\text { Pollutant } \\
\text { name }\end{array}$} & \multirow[b]{2}{*}{$\begin{array}{c}\text { Industrial } \\
\text { pollution } \\
\text { sources }\end{array}$} & \multicolumn{4}{|c|}{ Equivalent load of varieties pollution sources $\left(10^{6} \mathrm{~m}^{3} / \mathrm{a}\right)$} & \multirow[b]{2}{*}{$\begin{array}{c}\text { Fisheries } \\
\text { pollution } \\
\text { sources }\end{array}$} & \multirow[b]{2}{*}{$\begin{array}{c}\text { Equivalent } \\
\text { pollution load } \\
10^{6} \mathrm{~m}^{3} / \mathrm{a}\end{array}$} & \multirow[b]{2}{*}{ Load ratio (\%) } \\
\hline & & $\begin{array}{l}\text { Agricultural } \\
\text { pollution } \\
\text { sources }\end{array}$ & $\begin{array}{c}\text { Domestic } \\
\text { pollution } \\
\text { sources }\end{array}$ & $\begin{array}{c}\text { Tourism } \\
\text { pollution } \\
\text { sources }\end{array}$ & $\begin{array}{c}\text { Water traffic } \\
\text { pollution } \\
\text { sources }\end{array}$ & & & \\
\hline COD & 34.58 & 1278.95 & 179.16 & 12.48 & - & 5.62 & 1510.79 & 14.71 \\
\hline $\mathrm{TP}$ & - & 2930.15 & 134.35 & 7.80 & - & 3.10 & 3075.40 & 29.94 \\
\hline $\begin{array}{c}\text { Ammonia } \\
\text { nitrogen }\end{array}$ & 4.60 & 4803.45 & 268.74 & 15.6 & - & 4.94 & 5097.33 & 49.62 \\
\hline Oil & - & - & - & - & 533.4 & - & 533.4 & 5.19 \\
\hline As & 19.90 & - & - & - & - & - & 19.90 & 0.19 \\
\hline $\mathrm{Cd}$ & 33.60 & - & - & - & - & - & 33.60 & 0.33 \\
\hline $\mathrm{Pb}$ & 2.16 & & - & - & - & - & 2.16 & 0.02 \\
\hline Total load & 94.84 & 9012.55 & 582.25 & 35.88 & 533.4 & 13.64 & 10272.58 & 100.00 \\
\hline $\begin{array}{c}\text { Load ratio } \\
\text { (\%) }\end{array}$ & 0.92 & 87.74 & 5.67 & 0.35 & 5.19 & 0.13 & - & - \\
\hline Rank & 4 & 1 & 2 & 5 & 3 & 6 & & \\
\hline
\end{tabular}




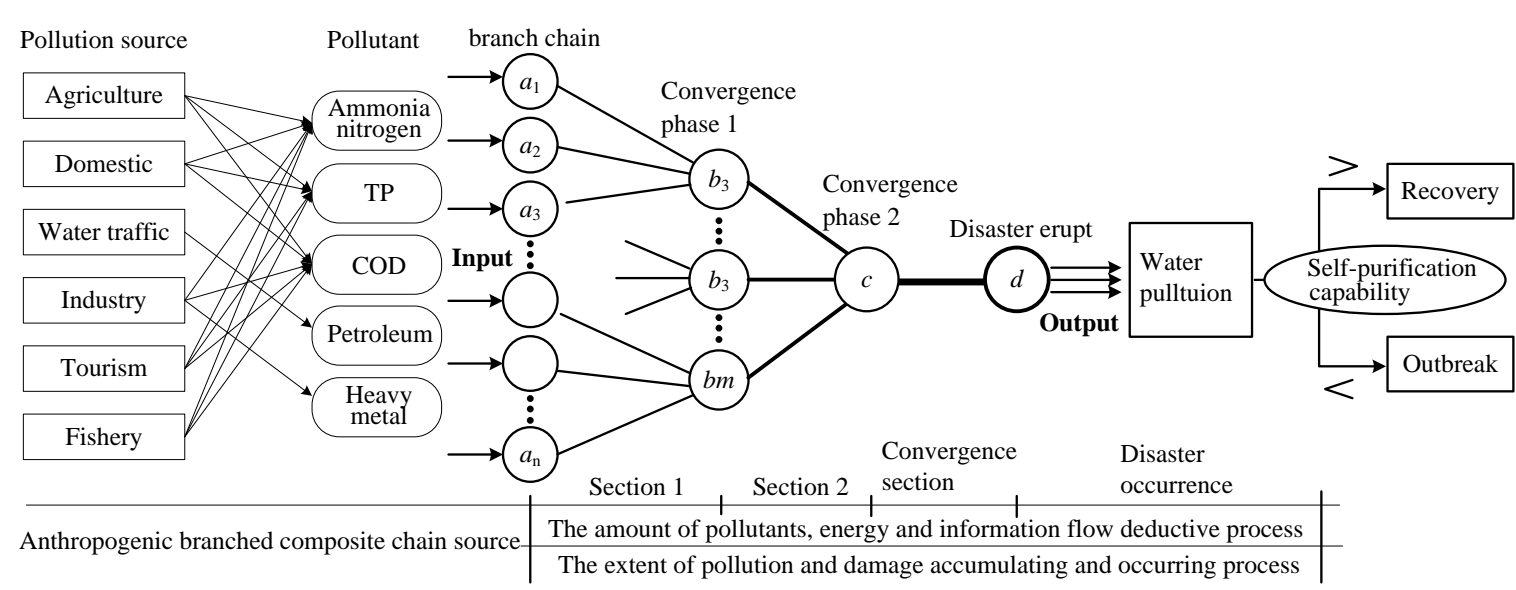

Figure 3. Disaster chain of water environment pollution of Dongjiang Lake.

$D(i(j))=\{D(i(j)) \mid j=1,2, \cdots, k ; k \geq 2\}$ reacts with disaster $D(i)$, who leads to a sub-chain, on the action of the external environment, and the relationship when disaster $D(i(j))$ reacts with $D(i)$ is $r_{D}^{i, i(j)}$ at time $t$. So it can be inferred that there has the following effect relationship between the response status $S_{D}^{i}$, the internal structural relationship $R_{D}^{i}$ and external behavior $H_{D}^{i}$ of disaster $D(i)$ and disaster $D(i)$ based on system theory:

$$
\begin{aligned}
& \phi_{1}\left(S_{o}(t), R_{o}(t),\left\{S_{D}^{i(j)}(t), R_{D}^{i(j)}(t) \mid j=1,2, \cdots, k ; k \geq 2\right\}, R_{D}^{i}(t)\right)=0 \\
& \phi_{2}\left(S_{o}(t),\left\{S_{D}^{i(j)}(t) \mid j=1,2, \cdots, k ; k \geq 2\right\}, R_{D}^{i}(t), S_{D}^{i}(t)\right)=0 \\
& \phi_{3}\left(S_{o}(t),\left\{R_{D}^{i(j)}(t) \mid j=1,2, \cdots, k ; k \geq 2\right\}, R_{D}^{i}(t), H_{D}^{i}(t)\right)=0
\end{aligned}
$$

Obviously, disaster (water environment pollution caused by pollutants) is a responsive behavior on the coupling effect of external (artificial) numerous environment (pollution sources production environment) factors. Formula 4 to 6 show that only when mutual effect relations established between the water environment pollution disasters, will it perform the burst of hazardous effects and aggregation of matter, energy and information. Also it could be argued that there exist discontinuity and concealment between coupling relationship and the convergence of water environment disaster. Moreover, because the external environment on the coupling process of multi-source disasters caused by pollution sources (this can be considered as a carrier of heavy metal migration process or branches watershed environment), with uncertainty and ambiguity on this coupling relation, water environment disasters chain shows the protracted nature and latency.

\subsection{Chain-Cutting Disaster Mitigation from Gestation Source of Water Pollution}

Chain-cutting disaster mitigation from gestation source refers to that damaging efforts is too weak to form a destruction on the early formation of the disaster chain, namely embryonic stage, and the energy is also on the initial stages of gathering or coupling. Chain-cutting disaster mitigation is the most efficient for cutting catastrophe during a long evolution process [12]. To control the water environment disaster chain in the Dongjiang Lake with chain-network structure of branches basin, the all-direction control for gestation source conditions is needed, namely the source management, monitoring and technical disposal of the 6 major pollution sources.

1) Water transportation, tourism and fishery pollution control. As for the direct discharge of pollutants, water transportation and tourism should perfect laws and regulations, strengthen supervision and management, such as the prohibition of solid pollutants into water, the recycling of residual or waste oil, the discharge standard must be met before exhausting oily wastewater, and the timely salvage of charged oil stain. In Fishery, project of cage culture reduction and making a living on land has achieved great results.

2) Agricultural and domestic pollution control. Actually, the transformation process between agricultural practices and non-point source pollution is relatively complicated, so we do not have much successful experiences for the control and prevention of agricultural nonpoint source pollution on the international currently, 
which shows the arduousness and protracted nature of its governance. In the long term, technological progress and institutional innovation is still fundamental way to solve the nonpoint source pollution [13].

Besides policy system, the domestic pollution control also requires technical means, mainly including the construction of domestic sewage treatment plants; the centralized treatment of living garbage from surrounding area; the implementation of rural households toilets amelioration, improving stoves and biogas utilization project; the establishment of the ecological model village project with the New Rural Construction in China.

3) Control of industrial pollution and heavy metals. The heavy metal pollution of Dongjiang Lake mainly comes from the mining, processing and smelting industry, which is the key to control pollutions from the source and upstream of industry. At the beginning of this century, in order to protect the Dongjiang Lake, Chenzhou government has promoted a shift in the mode of economic development. Through the integration of resources, coalmines were reduced from 576 to 270, and metal mines from 177 to 128 in Chenzhou area. As shown in Figure 4, on the surrounding of the Dongjiang Lake basin, six main ore districts, including Nanmuxia tungsten ore district, Qingyao town tungsten ore district, Qingjiang lead-zinc mining area, Dongping gold field, Chukou tungsten ore district, and Lianping tungsten ore district had been closed by the year 2008.

Essentially, the cut off emissions of pollutant from the head stream achieved the primary chain-cutting disaster mitigation from gestation source measures. At the same time, the ecological restoration and environment management of mining area around the Dongjiang Lake were carried out, which can be regarded as the secondary chain-cutting disaster mitigation from gestation source of pollution (heavy metals) resistance control, as you can see in Figure 5. The technologies are mainly as follows.

Firstly, land rehabilitation of breeding and growing specialized plants, such as Alnus cremastogyne Burk, Quercus virginiana, Rhus chinensis, K. striata, vetch and so on, are the most economic and effective approach to control the removal of heavy metals $\mathrm{Pb}, \mathrm{Zn}, \mathrm{Cu}$ in environment. It plays an inactivation of the heavy metals in polluted soil based on combined effect of the target species and chemical scavenger.

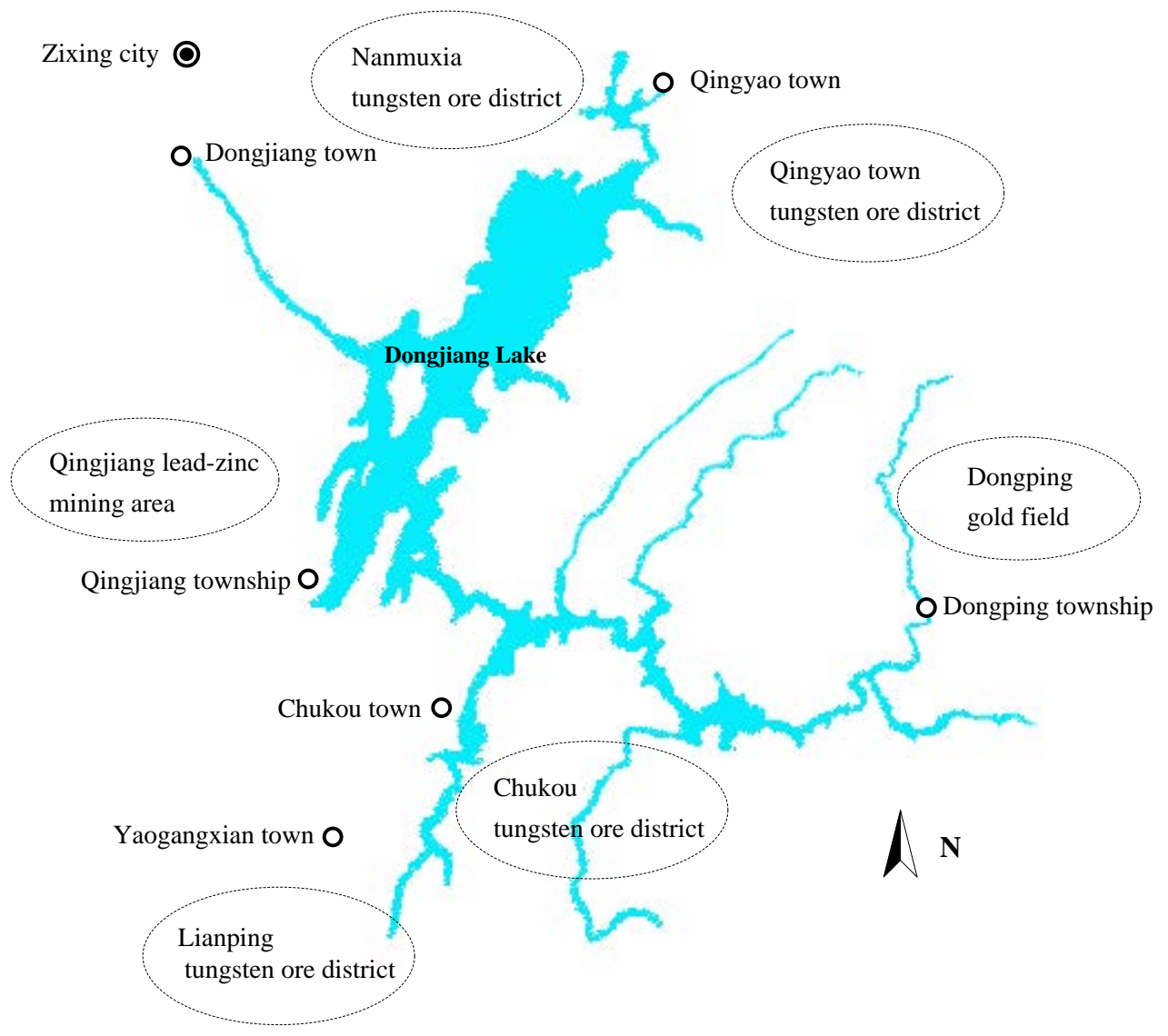

Figure 4. Main ore districts distribution around Dongjiang Lake. 


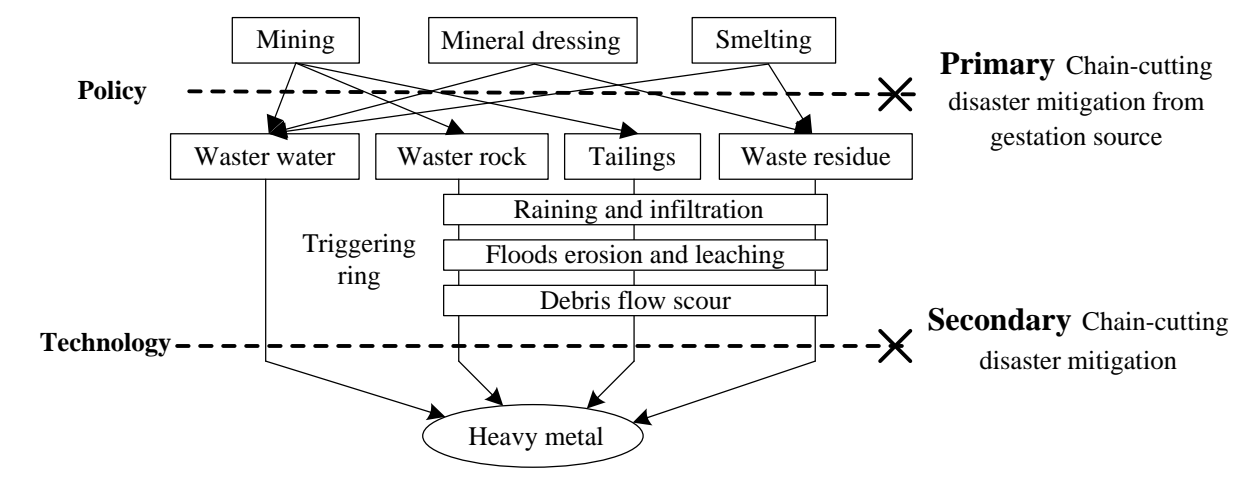

Figure 5. Chain-cutting measures of heavy metal control.

Secondly, for ecological treatment and intercept of soil and water pollution, permeable reactive barrier (PRB) and ecological gully were built in the right place.

Thirdly, resource utilization of soil contained heavy metals, tailings, waste rock and waste residue was studied, including producing cement with lead-zinc tailings, environmental friendly cementation materials with tailings and waste residue in non-ferrous smelting.

Fourthly, by hazard identification, risk assessment, testing and monitoring on industrial sites such as tailings dam and open pit slopes, disasters avoid heavy rainfall and take control of heavy metals removal effectively.

\section{Conclusion}

This paper developed the research of disaster chain to regional water environment security research, and discussed the connotation of regional environment disaster chain. Under the background of water pollution in the Dongjiang Lake, this paper carried out the definition and evaluation of pollution disaster resources in regional water environment of the Dongjiang Lake and analyzed the major sources of water pollution in the lake. Combining disaster chain theory, the disaster chain model of regional water environment pollution in the Dongjiang Lake is constructed, and the Dongjiang Lake water pollution generally belongs to the multisource disaster implication chain caused by human activities, which possess features of branches and trunk basin disaster chain with incubation period in a long term. In this paper, we also proposed primary and secondary chain-cutting disaster mitigation from gestation source thought on regional water environment governance, with emphasis on technology of ecological restoration and heavy metal control in mining area.

\section{Acknowledgements}

This work is supported by the Natural Science Foundation of China (Grant No. 51204205) and the National Science and Technology Support Program of China in the 12th Five-Year Plan (Grant No. 2012BAC09B02).

\section{References}

[1] Zhang, X.B. and Li, X. (2013) Research on the Progress and Tendency of Water Environment Safety in China. Safety and Environment Engineering, 1, 122-137.

[2] Guo, Z.J. and Qin, B.Y. (1987) Brief Discussion on Disaster Physics. Journal of Catastrophology, 2, 25-33.

[3] Wen, C.J. (2000) Generalized Disaster, Disaster Chain and Their Prevention and Control. Journal of Catastrophology, 4, 13-18.

[4] Shi, P.J. (2002) Theory on Disaster Science and Disaster Dynamic. Journal of Natural Disasters, 3, 1-9.

[5] Men, K.P. and Gao, J.G. (2008) Severe Disaster Chain and Its Defense. Progress in Geophysics, 1, $270-275$.

[6] Xiao, S.X. (2006) Catastrophic Chain-Styled Theory and Application. Science Press, Beijing.

[7] Academic Department of China Association for Science and Technology (2009) Evolution Process, ForecastingMethodsand Countermeasure of Major Disaster Chain. Press of Science and Technology of China, Beijing.

[8] Peng, Y.H. and Zhou, K.P. (2014) Case Study on Evolution of Industry Structure and the Response of Water Environment of Dongjiang Lake Basin. Acta Agriculturae Universitatis Jinangxiensis, 5, 1152- 1158. 
[9] Hunan Provincial Environmental Protection Science Academy (2010) The Dongjiang Lake Basin Water Environment Protection Plan.

[10] He, W., Ou, L.Y., Chen, X.Y., Zhang, Z.J., Liao, F.C., Huang, X.R. and Zeng, C.F. (2009) Dynamic Changes and Evaluation of Fisheries Water in Dongjian Lake. Journal of Hydroecology, 2, 139-144.

[11] Xiao, S.X. (2006) Originality Structure Sketch on Chain-Styled Theory of Disaster in Eco-Environment. Chinese Journal of Rock Mechanics and Engineering, 1, 2593-2602.

[12] Xiao, S.X., Sui, Y.C., Liu, W.F. and Zhou, J.F. (2007) Application of Chain-Cutting Disaster Mitigation from Gestation Source to Preventing Land Desertification. Journal of Chongqing Jiao Tong University, 3, 149-152.

[13] Wesstrom, I., Joel, A. and Messing, I. (2014) Controlled Drainage and Subirrigation-A Water Management Option to Reduce Non-Point Source Pollution from Agricultural Land. Agriculture Ecosystems \& Environment, 12, 74-82. http://dx.doi.org/10.1016/j.agee.2014.03.017 